\title{
Levantamento etnobotânico na Comunidade Rural de Santa Marta, Município de Corrente, Estado do Piauí, Nordeste do Brasil
}

\section{Cecília de Souza Carvalho', Patrine Nunes Gomes ${ }^{1}$, Luzirrany Soares Lopes ${ }^{1}$, Miria Cassia Oliveira Aragão², Lizandro Pereira de Abreu ${ }^{1}, *$ e Marcília Martins da Silva ${ }^{1}$}

${ }^{1}$ Instituto Federal do Piauí. Campus Corrente. Rua Projetada 06, 380. Nova Corrente. Corrente-PI, Brasil (CEP 64980-000). *E-mail: lizandro.abreu@ifpi.edu.br ${ }^{2}$ Instituto Federal do Piauí. Campus Floriano. Rua Francisco Urquiza Machado, 462. Bairro Meladão. Floriano-PI, Brasil (CEP 64808-475).

Resumo. O Brasil é um país bastante rico em biodiversidade e com isso as comunidades tradicionais e agricultores fazem o cultivo dessa ampla diversidade de espécies e de variedades vegetais. Este fator agrega grande relevância aos estudos etnobotânicos, onde busca-se resgatar o conhecimento sobre as plantas nas comunidades rurais, visando manter a interrelação entre a utilização de plantas medicinais e o conhecimento das pessoas. 0 presente estudo teve como objetivo verificar o perfil socioeconômico e a percepção das pessoas sobre o conhecimento botânico do uso e apropriação das plantas medicinais utilizadas na comunidade rural de Santa Marta, Município de Corrente, Estado do Piauí. A pesquisa foi realizada no período de julho de 2018 a março de 2019, na Comunidade Rural de Santa Marta, sendo ela destinada às pessoas com idade igual ou superior a 40 anos, em virtude de possuírem mais conhecimento sobre o uso de plantas medicinais. Para isso, foi realizada uma caminhada transversal com alguns moradores e a aplicação de um questionário semiestruturado de caráter quali-quantitavo. Foi registrado um total de 90 espécies de plantas medicinais utilizadas pelos moradores da Comunidade Rural de Santa Marta. Após identificar as espécies juntamente com os moradores e ainda com a realização de levantamentos bibliográficos, verificouse que muitas destas espécies são típicas do Cerrado, mas existem a ocorrência de algumas predominantes da Caatinga e Mata Atlântica. As espécies mais usadas pelos entrevistados são a erva-doce Pimpinella anisum L. e o hortelã Mentha crispa L., mencionadas por cerca de $36,36 \%$ dos entrevistados, a melancia-da-praia Solanum agrarium Sendtn. (27,27\%), a erva-cidreira Lippia alba Mill. N.E.Br. (18,18\%), seguido do alecrim Rosmarinus officinalis L., do gengibre Zingiber officinale Roscoe, da imburana Amburana cearensis A.C. Smith e do limão Citrus limon L. Burm. $(13,64 \%)$ e do pequi Caryocar coriaceum Wittm $(4,54 \%)$. Dentre as espécies identificadas muitas delas são
Recebido $18 / 04 / 2020$

Aceito

$06 / 12 / 2020$

Disponível on line

$07 / 12 / 2020$

Publicado

$31 / 12 / 2020$

Acesso aberto

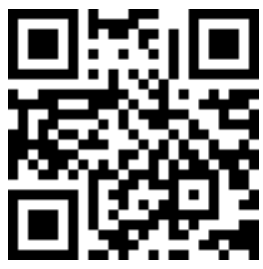

ORCID

(ㄷ) 0000-0003-1362-4077 Cecília de Souza Carvalho

(D) 0000-0002-9201-6928 Patrine Nunes Gomes

D 0000-0003-1698-1029 Luzirrany Soares Lopes

ISSN 2359-1412/RBGAS-2020-0062/2020/7/17/28/1483

Rev. Bras. Gest. Amb. Sustent.

http://revista.ecogestaobrasil.net 
utilizadas para o tratamento de enfermidades que acometem a vida das pessoas como, diarreia, hipertensão, infecção no sistema urinário, colesterol, entre outros. Quanto à parte vegetal utilizada nas preparações dos remédios caseiros, observou-se uma frequência maior de uso das folhas, seguido de caule e fruta, raízes, flores e óleo. Por meio das informações obtidas foi possível realizar o levantamento etnobotânico das plantas medicinais utilizadas na Comunidade Rural de Santa Marta e, além disso, do uso e do conhecimento que as pessoas possuem. Ao construir essa relação entre comunidade e o conhecimento sobre uso das plantas medicinais, torna-se de grande valia para a vida das pessoas, propiciando a contribuição para a conservação da cultura regional, contribuindo assim na sua valorização.

Palavras-chave: Cerrado; Flora; Percepção.

Abstract. Ethnobotanical survey in the Rural Community of Santa Marta, Municipality of Corrente, Piauí State, Northeast of Brazil. Brazil is a country rich in biodiversity, where traditional communities and farmers cultivate this great diversity of plant species and varieties. This factor adds great relevance to ethnobotanical studies, which seek to preserve knowledge about plants in rural communities, aiming to maintain the interrelation between the use of medicinal plants and popular knowledge. The present study aimed to verify the socioeconomic profile and people's botanical knowledge of the use of medicinal plants in the Rural Community of Santa Marta, located in the Municipality of Corrente, Piauí, Brazil. The study was carried out from July 2018 to March 2019, in the Rural Community of Santa Marta, aimed at people aged 40 years or older, due to their greater knowledge about the use of medicinal plants. For this, a cross-sectional survey was carried out with some residents with the application of a semi-structured questionnaire of a quali-quantitative character. A total of 90 species of medicinal plants used by residents of Santa Marta were recorded. After identifying the species together with the inhabitants and also carrying out bibliographic surveys, we found that many of these species are typical of the Cerrado biome, but some predominate in the Caatinga and Atlantic Forest biomes. The species most used by the respondents were aniseed Pimpinella anisum L. and spearmint Mentha crispa L., mentioned by about $36.36 \%$ of the respondents, followed by purple nightshade Solanumagrarium Sendtn. (27.27\%), lemongrass Lippia alba Mill. NEBr. (18.18\%), rosemary Rosmarinus officinalis L., ginger Zingiber officinale Roscoe, imburana Amburana cearensis AC Smith, lime Citrus limon L. Burm. (13.64\%) and pequi Caryocar coriaceum Wittm (4.54\%). Among the identified species, many are used to treat diseases such as diarrhea, hypertension, urinary system infection and high cholesterol, among others. As for the plant parts used in the preparation of home remedies, a higher frequency of use of leaves was observed, followed by stems and fruits, roots, flowers and oil. The ethnobotanical survey of the medicinal plants used in the
D) 0000-0002-0101-4696 Miria Cassia Oliveira Aragão

(1) 0000-0001-6427-3356 Lizandro Pereira de Abreu

D 0000-0002-4906-7965 Marcília Martins da Silva 
Rural Community of Santa Marta provided valuable information about the use and knowledge people have. Understanding this relationship between the community and knowledge about the use of medicinal plants makes a valuable contribution to the conservation of regional culture, thus contributing to its valorization.

Keywords: Cerrado; Flora; Perception.

\section{Introdução}

O conhecimento advindo sobre o uso das plantas medicinais vem desde muitos anos atrás, cultura a qual é bastante utilizada pelas comunidades, sendo elas rurais, indígenas, entre outras.

As comunidades possuem uma rica diversidade de espécies vegetais, e essas fazem a utilização de plantas desde os primórdios da evolução humana, onde vem-se desenvolvendo maneiras de comprovar suas finalidades, tornando-as uma alternativa viável benéfica para a saúde das pessoas (Souza et al., 2017).

Atualmente, a etnobotânica pode ser entendida como a ciência que estuda a interrelação direta entre os povos e a utilização de plantas medicinais, bem como as concepções desenvolvidas sobre o aproveitamento que se faz delas. Para isso, foram criadas ciências voltadas para a investigação, instrução e para aprimorar o conhecimento que as pessoas possuem sobre o uso das plantas medicinais (Albuquerque et al., 2008; Pauli et al. (2018).

Com o avanço da tecnologia foram criados novos métodos voltados para a melhoria da qualidade de vida das pessoas, como a substituição do uso de plantas medicinais por medicamentos fitoterápicos, isso ocorre pelo fato de serem encontrados com maior facilidade e seus benefícios serem clinicamente comprovados, fato que vem fazendo com que as pessoas percam o interesse pelos costumes e hábitos comuns das comunidades.

No geral essas comunidades possuem conhecimento quanto ao uso de plantas medicinais e suas indicações mais frequentes no processo de cura e alívio de muitos problemas de saúde que acometem a vida das pessoas. No entanto, nos últimos anos muitos autores têm questionado se o conjunto relacionado ao conhecimento popular e uso de plantas têm perdido a sua relevância, isso em decorrência do êxodo rural, onde as novas gerações presente nestas comunidades estão migrando cada vez mais para as zonas urbanas, ocorrendo desse modo um distanciamento dos conhecimentos e costumes das comunidades (Franco e Barros, 2006; Souza, 2015).

E com isso, as preocupações têm sido crescentes em relação a tal afastamento, sem mencionar os impactos que o ecossistema brasileiro vem sofrendo em virtude das ações antrópicas, fator que vem ocasionando perda de grande parte da biodiversidade tanto na fauna quanto na flora (Messias e Carmo, 2015). É de extrema importância que sejam mantidos estudos etnobotânicos para que dessa maneira sejam realizados o resgate e o registro do conhecimento tradicional que é transmitido de geração para geração os quais são mantidos principalmente pela oralidade, e com isso evitando a sua perda com o passar do tempo.

Segundo Lima (2013), deve-se levar em consideração a inter-relação entre o conhecimento e as comunidades no que se refere ao uso das plantas medicinais, bem como a conservação destas, fato este que torna a pesquisa etnobotânica de extrema importância, pois permite que sejam realizados estudo relacionados ao resgate do conhecimento, além da conservação da biodiversidade de maneira sustentável. 
Contudo, tem-se intensificado cada vez mais os estudos etnobotânicos, por serem consideradas importantes para as comunidades, isso em virtude de serem de fácil acesso, principalmente nas zonas rurais sem mencionar que são menos onerosas.

A utilização de plantas medicinais é tida como uma prática viável no tratamento de enfermidades, e com isso tal estudo passou a ser necessário para que fosse feito a identificação, além disso verificar a sua importância (Lopes Sobrinho et al., 2018). A coleta de dados referente ao uso de plantas medicinais possibilita o conhecimento sobre o tema, além de avaliar os benefícios que as espécies medicinais proporcionam e permitem ainda, a identificação das mesmas.

Nesta perspectiva, o presente estudo teve como objetivo realizar o levantamento etnobotânico de plantas medicinais do uso e apropriação de espécies nativas do Cerrado utilizadas na Comunidade Rural de Santa Marta, Município de Corrente (PI).

\section{Metodologia}

\section{Área de estudo}

A pesquisa foi realizada no Município de Corrente, na zona rural, localidade de Santa Marta, situada na Microrregião do Extremo Sul Piauiense (Figura 1), no bioma cerrado. 0 município compreende uma área de $3.048 .447 \mathrm{~km}^{2}$ com uma população de 26.084 habitantes, corresponde a uma densidade demográfica de $8,33 \mathrm{hab} / \mathrm{km}^{2}$, sendo a população urbana de 15.693 habitantes e rural 10.391, segundo o último censo demográfico realizado pelo Instituto Brasileiro de Geografia e Estatística (IBGE, 2015).
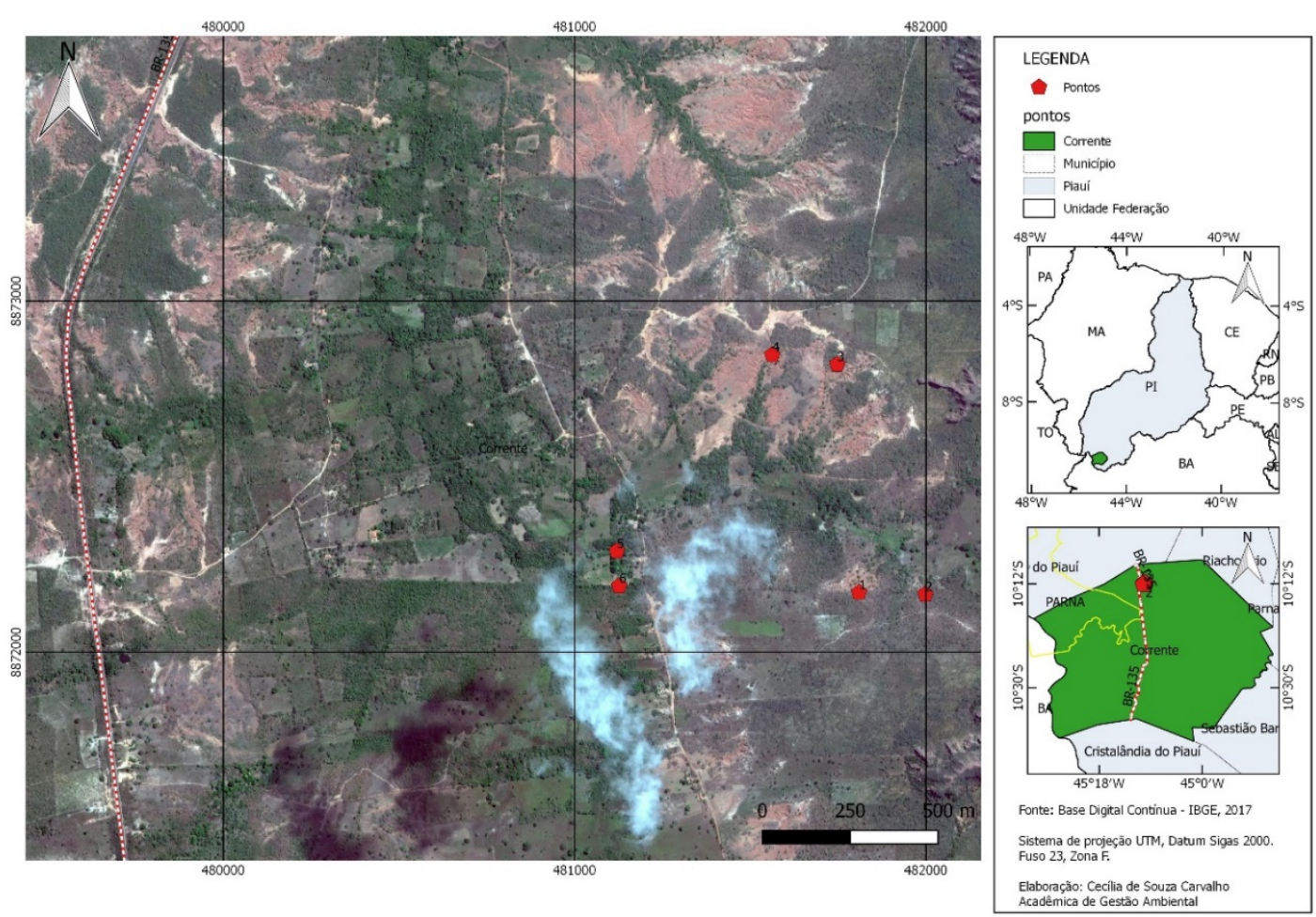

Figura 1. Localização de Santa Marta, Município de Corrente-PI. 


\section{Procedimentos metodológicos}

A pesquisa etnobotânica foi realizada no período de julho de 2018 a março de 2019, realizada na comunidade rural. Sendo essa selecionada como área de estudo por possuir uma rica diversidade em espécies e pelo fato de que ainda não existe conservação dos recursos naturais. Inicialmente foram realizados levantamentos bibliográficos no que se refere a vegetação no que se refere a sua conservação, uso, apropriação, formas de utilização e suas principais indicações das espécies medicinais nas comunidades rurais. Posteriormente, foram realizadas visitas in loco para que fosse possível adquirir dados da pesquisa.

Os dados obtidos foram catalogados em uma tabela para possibilitar uma melhor compreensão dos mesmos e foram ainda, analisados comparativamente aos constantes na literatura, identificado por meio das informações passadas pelos morados da comunidade quanto ao nome popular, as formas de uso e as principais espécies utilizadas, os nomes científicos foram verificados em sites, e artigos científicos (Baptistel et al., 2014; Bastos et al., 2018; Lima, 2013; Rodrigues e Andrade 2014).

Foram realizados ainda, registros fotográficos das espécies identificadas, a coleta de coordenadas por meio do GPS (Global Positioning System) e ainda do o uso do QGIS Desktop 2.14.8 programa de Sistema de Informação Geográfica (SIG) Desktop 2.14.8 para realizar confeccionar o mapa de localização da área de estudo.

\section{Caminhada transversal}

A primeira etapa foi realizada por meio de uma caminhada transversal com alguns moradores mais velhos da comunidade, isso em virtude de os mesmos possuírem mais conhecimento sobre as plantas no que se refere as indicações de uso.

De acordo Minayo et al. (2009), são abordadas questões relacionadas a pesquisas cientificas trazendo a abordagem de conceitos básicos, por meio da pesquisa social, buscando desse modo, meios concretos que especifiquem determinada realidade de um dado local, onde no labor científico tem como pressuposto a elaboração de teorias que visem a obtenção de resultados no que se refere aos métodos e princípios de determinado estudo.

Nessa linhagem, é possível por meio da investigação e da aproximação com as pessoas, verificar os costumes que determinada sociedade possui proporcionando a construção do conhecimento e com isso havendo a colaboração no histórico do uso de plantas medicinais. E por meio desta, foi possível realizar a identificação das espécies, onde realizou-se a tabulação dos dados obtidos, posteriormente.

\section{Resultados e discussão}

\section{Levantamento etnobotânico}

No primeiro momento da pesquisa realizada por meio da caminhada transversal foram citadas e identificadas com o apoio dos anciões, residentes da comunidade 90 espécies de plantas medicinais, sendo estas pertencentes a 41 famílias botânicas (Tabela 1). Destas, as que apresentaram maior número de espécies foram a Fabaceae (13), Lamiaceae (6), Anacardiaceae (5), Rutaceae (5), Asteraceae (5), Euphorbiaceae (5), Myrtaceae (4), Malvaceae (3), Liliaceae (3), Zingiberaceae (2), Moraceae (2), Bignoniaceae (2), Apiaceae (2), Rubiaceae (2), Solanaceae (2), Cactaceae (2), Apocynaceae (2), Amaranthaceae (2) e as demais com uma espécie cada. 
Tabela 1. Lista de espécies medicinais indicadas pelos entrevistados da Comunidade Rural de Santa Marta, Município de Corrente-PI.

\begin{tabular}{|c|c|c|c|c|c|}
\hline Família/NP & NC & PU & $\begin{array}{c}\text { Forma de } \\
\text { preparo }\end{array}$ & Indicação & $\begin{array}{c}\text { Frequência } \\
\text { de citação }\end{array}$ \\
\hline \multicolumn{6}{|c|}{ Amaranthaceae } \\
\hline Mastruz & $\begin{array}{l}\text { Chenopodium } \\
\text { ambrosioides L. }\end{array}$ & $\begin{array}{l}\text { Planta } \\
\text { inteira }\end{array}$ & $\begin{array}{l}\text { Cataplasma, } \\
\text { decocto, } \\
\text { xarope, } \\
\text { infusão, suco }\end{array}$ & $\begin{array}{l}\text { Vermífuga, } \\
\text { antibiótico, } \\
\text { mal-estar, fígado, } \\
\text { esfoliações }\end{array}$ & $9,09 \%$ \\
\hline Paratudo & $\begin{array}{l}\text { Gomphrena } \\
\text { arborescens L. f. }\end{array}$ & Raiz & Infusão & $\begin{array}{l}\text { Diarreia, febre, } \\
\text { fraqueza }\end{array}$ & $9,09 \%$ \\
\hline \multicolumn{6}{|c|}{ Anacardiaceae } \\
\hline Aroeira & $\begin{array}{l}\text { Myracrodruon } \\
\text { urundeuva } \\
\text { M.Allemão. } \\
\end{array}$ & Caule & Maceração & $\begin{array}{l}\text { Inflamações, rins, } \\
\text { estômago, } \\
\text { cicatrizante }\end{array}$ & $9,09 \%$ \\
\hline Caju & $\begin{array}{l}\text { Anacardium } \\
\text { occidentale L. }\end{array}$ & Folha & Suco & $\begin{array}{l}\text { Febre, gripe, } \\
\text { cefaleia, dor de } \\
\text { dente, ferimento }\end{array}$ & $4,54 \%$ \\
\hline $\begin{array}{l}\text { Gonçalo } \\
\text { Alves }\end{array}$ & $\begin{array}{l}\text { Astronium } \\
\text { fraxinifolium } \\
\text { Schott ex Spreng. }\end{array}$ & Caule & $\begin{array}{l}\text { Chá fervido, } \\
\text { decocto }\end{array}$ & $\begin{array}{l}\text { Tosse, gripe, } \\
\text { coluna, febre }\end{array}$ & $9,09 \%$ \\
\hline Manga & $\begin{array}{l}\text { Mangifera indica } \\
\text { L. }\end{array}$ & Folha & $\begin{array}{l}\text { Decocto, } \\
\text { infusão, } \\
\text { xarope }\end{array}$ & $\begin{array}{l}\text { Inflamação dos } \\
\text { dentes }\end{array}$ & $4,54 \%$ \\
\hline Seriguela & $\begin{array}{l}\text { Spondias } \\
\text { purpurea L. }\end{array}$ & Caule & Decocto & Gripe, febre & $4,54 \%$ \\
\hline \multicolumn{6}{|l|}{ Annonaceae } \\
\hline Ata & $\begin{array}{l}\text { Annona } \\
\text { squamosa L. }\end{array}$ & Folha & $\begin{array}{l}\text { Infusão, } \\
\text { decocto }\end{array}$ & $\begin{array}{l}\text { Dor de estomago e } \\
\text { febre }\end{array}$ & $9,09 \%$ \\
\hline \multicolumn{6}{|l|}{ Apiaceae } \\
\hline Coentro & $\begin{array}{l}\text { Coriandrum } \\
\text { sativum } \mathrm{L} .\end{array}$ & $\begin{array}{l}\text { Caule, } \\
\text { folha, } \\
\text { fruto, } \\
\text { raiz }\end{array}$ & $\begin{array}{l}\text { Infusão, } \\
\text { decocto }\end{array}$ & $\begin{array}{l}\text { Melhora os níveis } \\
\text { de colesterol, } \\
\text { antioxidante }\end{array}$ & $9,09 \%$ \\
\hline Erva doce & $\begin{array}{l}\text { Pimpinella } \\
\text { anisum L. }\end{array}$ & $\begin{array}{l}\text { Semente } \\
\text { folha }\end{array}$ & Decocto & Febre, cólicas & $36,36 \%$ \\
\hline \multicolumn{6}{|c|}{ Apocynaceae } \\
\hline Mangaba & $\begin{array}{l}\text { Hancornia } \\
\text { speciosa Gomes }\end{array}$ & $\begin{array}{l}\text { Caule, } \\
\text { folha, } \\
\text { látex }\end{array}$ & Maceração & $\begin{array}{l}\text { Coluna, Gastrite, } \\
\text { hipertensão, } \\
\text { câncer, tireoide }\end{array}$ & $9,09 \%$ \\
\hline Tiborna & $\begin{array}{l}\text { Himatanthus } \\
\text { obovatus (Mull. } \\
\text { Arg.) }\end{array}$ & Caule & Decocto & $\begin{array}{l}\text { Anti-inflamatória, } \\
\text { cicatrizante }\end{array}$ & $4,54 \%$ \\
\hline \multicolumn{6}{|l|}{ Arecaceae } \\
\hline Buriti & $\begin{array}{l}\text { Mauritia flexuosa } \\
\text { L.f }\end{array}$ & $\begin{array}{l}\text { Fruto } \\
\text { (óleo) }\end{array}$ & $\begin{array}{l}\text { Uso do óleo } \\
\text { em ferimentos }\end{array}$ & $\begin{array}{l}\text { Energético e } \\
\text { vermífugo, ajuda } \\
\text { na cicatrização }\end{array}$ & $9,09 \%$ \\
\hline
\end{tabular}


Tabela 1. Continuação.

\begin{tabular}{|c|c|c|c|c|c|}
\hline Família/NP & NC & PU & $\begin{array}{c}\text { Forma de } \\
\text { preparo }\end{array}$ & Indicação & $\begin{array}{c}\text { Frequência } \\
\text { de citação }\end{array}$ \\
\hline \multicolumn{6}{|l|}{ Asteraceae } \\
\hline Assapeixe & $\begin{array}{l}\text { Vernonia } \\
\text { ferruginea Less }\end{array}$ & $\begin{array}{l}\text { Folha, } \\
\text { raiz }\end{array}$ & Decocto & $\begin{array}{l}\text { Bronquite, } \\
\text { machucados, } \\
\text { depurativo }\end{array}$ & $9,09 \%$ \\
\hline Camomila & $\begin{array}{l}\text { Matricaria } \\
\text { chamomilla L. }\end{array}$ & Flor & Infusão & $\begin{array}{l}\text { Ansiedade, } \\
\text { inflamações } \\
\text { nasais, má } \\
\text { digestão, diarreia }\end{array}$ & $9,09 \%$ \\
\hline Carqueja & $\begin{array}{l}\text { Baccharis } \\
\text { trimera (Less) } \\
\text { DC }\end{array}$ & $\begin{array}{l}\text { Folha, } \\
\text { caule }\end{array}$ & Decocção & Digestivo & $9,09 \%$ \\
\hline Mentrasto & $\begin{array}{l}\text { Ageratum } \\
\text { conyzoides (L.) L. }\end{array}$ & $\begin{array}{l}\text { Caule, } \\
\text { flor, } \\
\text { folha, } \\
\text { raiz }\end{array}$ & $\begin{array}{l}\text { Decocto, } \\
\text { infusão }\end{array}$ & $\begin{array}{l}\text { Cólica menstrual, } \\
\text { dor estomacal }\end{array}$ & $9,09 \%$ \\
\hline Vique & Mentha sp. & Folha & $\begin{array}{l}\text { Banho, } \\
\text { decocto, } \\
\text { infusão }\end{array}$ & $\begin{array}{l}\text { Gripe, inflamação } \\
\text { na garganta }\end{array}$ & $4,54 \%$ \\
\hline \multicolumn{6}{|l|}{ Bignoniaceae } \\
\hline Catuaba & $\begin{array}{l}\text { Anemopaegma } \\
\text { arvense (Vell.) } \\
\text { Stellfeld ex de } \\
\text { Souza } \\
\end{array}$ & Caule & $\begin{array}{l}\text { Infusão, } \\
\text { decocto }\end{array}$ & $\begin{array}{l}\text { Cansaço, } \\
\text { estimulante } \\
\text { energético, falta } \\
\text { de memória }\end{array}$ & $9,09 \%$ \\
\hline Pau d'arco & $\begin{array}{l}\text { Tabebuia } \\
\text { impetiginosa } \\
\text { Mart. et DC. } \\
\end{array}$ & Caule & $\begin{array}{l}\text { Decocto, } \\
\text { maceração }\end{array}$ & $\begin{array}{l}\text { Nervos, fígado, } \\
\text { rins }\end{array}$ & $9,09 \%$ \\
\hline \multicolumn{6}{|l|}{ Bixacea } \\
\hline Urucum & Bixa orellana L. & Semente & Decocto & $\begin{array}{l}\text { Colesterol, } \\
\text { diabetes }\end{array}$ & $4,54 \%$ \\
\hline \multicolumn{6}{|c|}{ Boranginaceae } \\
\hline Crista de galo & $\begin{array}{l}\text { Heliotropium } \\
\text { indicum } \mathrm{L} .\end{array}$ & $\begin{array}{l}\text { Folha, } \\
\text { flor }\end{array}$ & $\begin{array}{l}\text { Decocto, } \\
\text { infusão }\end{array}$ & $\begin{array}{l}\text { Hipertensão, } \\
\text { diarreia }\end{array}$ & $4,54 \%$ \\
\hline \multicolumn{6}{|c|}{ Bromeliaceae } \\
\hline Abacaxi & $\begin{array}{l}\text { Ananas comosus } \\
\text { L. Merr. }\end{array}$ & Fruto & Suco & Gripe, inflamação & $9,09 \%$ \\
\hline \multicolumn{6}{|l|}{ Cactaceae } \\
\hline Mandacaru & $\begin{array}{l}\text { Cereus jamacaru } \\
\text { DC. }\end{array}$ & Caule & Infusão & $\begin{array}{l}\text { Diabete, Infecção } \\
\text { do aparelho } \\
\text { geniturinário } \\
\text { feminino }\end{array}$ & $4,54 \%$ \\
\hline $\begin{array}{l}\text { Palma } \\
\text { (cacto) }\end{array}$ & $\begin{array}{l}\text { Opuntia ficus- } \\
\text { indica (L.) Mill. }\end{array}$ & $\begin{array}{l}\text { Caule, } \\
\text { fruto, } \\
\text { flor }\end{array}$ & Infusão & $\begin{array}{l}\text { Colesterol, } \\
\text { diabete, lesão na } \\
\text { pele }\end{array}$ & $9,09 \%$ \\
\hline \multicolumn{6}{|l|}{ Caricaceae } \\
\hline Mamão & Carica papaya L. & $\begin{array}{l}\text { Folha, } \\
\text { fruto }\end{array}$ & $\begin{array}{l}\text { Decocto, } \\
\text { infusão }\end{array}$ & $\begin{array}{l}\text { Cólicas intestinais, } \\
\text { má digestão e } \\
\text { regulador } \\
\text { intestinal }\end{array}$ & $9,09 \%$ \\
\hline
\end{tabular}


Tabela 1. Continuação.

\begin{tabular}{|c|c|c|c|c|c|}
\hline Família/NP & NC & PU & $\begin{array}{c}\text { Forma de } \\
\text { preparo }\end{array}$ & Indicação & $\begin{array}{c}\text { Frequência } \\
\text { de citação }\end{array}$ \\
\hline \multicolumn{6}{|c|}{ Caryocaraceae } \\
\hline Pequi & $\begin{array}{l}\text { Caryocar } \\
\text { coriaceum Wittm }\end{array}$ & Fruto & Azeite & $\begin{array}{l}\text { Gripe, furúnculo, } \\
\text { inchaço, } \\
\text { reumatismo }\end{array}$ & $9,09 \%$ \\
\hline \multicolumn{6}{|c|}{ Convolvulaceae } \\
\hline $\begin{array}{l}\text { Batata de } \\
\text { purga }\end{array}$ & $\begin{array}{l}\text { Operculina } \\
\text { macrocarpa } \\
\text { Urb. }\end{array}$ & Raiz & Suco & $\begin{array}{l}\text { Complemento } \\
\text { vitamínico, dor no } \\
\text { estomago, } \\
\text { constipação }\end{array}$ & $4,54 \%$ \\
\hline \multicolumn{6}{|l|}{ Cyperaceae } \\
\hline Tiririca & Cyperus sp. & Raiz & Decocto & $\begin{array}{l}\text { Infecção } \\
\text { garganta }\end{array}$ & $4,54 \%$ \\
\hline \multicolumn{6}{|l|}{ Cucurbitaceae } \\
\hline $\begin{array}{l}\text { Melão de São } \\
\text { Caetano }\end{array}$ & $\begin{array}{l}\text { Momordica } \\
\text { charantia L. }\end{array}$ & $\begin{array}{l}\text { Folha, } \\
\text { fruto }\end{array}$ & Decocto & Sarna, coceira & $9,09 \%$ \\
\hline \multicolumn{6}{|c|}{ Euphorbiaceae } \\
\hline Cansanção & $\begin{array}{l}\text { Cnidoscolus urens } \\
\text { (L.) Arthur }\end{array}$ & Raiz & $\begin{array}{l}\text { Decocto, } \\
\text { maceração }\end{array}$ & $\begin{array}{l}\text { Febre, diarreia, } \\
\text { gripe, picada de } \\
\text { cobra }\end{array}$ & $9,09 \%$ \\
\hline Mamona & $\begin{array}{l}\text { Ricinus } \\
\text { communis L. }\end{array}$ & Semente & Azeite, suco & $\begin{array}{l}\text { Cólicas } \\
\text { abdominais, } \\
\text { puerpério }\end{array}$ & $9,09 \%$ \\
\hline Quebra pedra & $\begin{array}{l}\text { Phyllanthus } \\
\text { niruri Vell. }\end{array}$ & $\begin{array}{l}\text { Planta } \\
\text { inteira, } \\
\text { folha }\end{array}$ & $\begin{array}{l}\text { Decocto, } \\
\text { maceração }\end{array}$ & $\begin{array}{l}\text { Infecção renal, } \\
\text { fígado }\end{array}$ & $4,54 \%$ \\
\hline Velame & $\begin{array}{l}\text { Croton } \\
\text { rhamnifolius } \\
\text { Kunth }\end{array}$ & Raiz & $\begin{array}{l}\text { Decocto, } \\
\text { infusão }\end{array}$ & $\begin{array}{l}\text { Febre, gripe, } \\
\text { diarreia, picada de } \\
\text { cobra }\end{array}$ & $9,09 \%$ \\
\hline \multicolumn{6}{|l|}{ Fabaceae } \\
\hline Barbatimão & $\begin{array}{l}\text { Stryphnodendron } \\
\text { adstringens } \\
\text { (Mart.) }\end{array}$ & Caule & $\begin{array}{l}\text { Banho, } \\
\text { decocto, pó }\end{array}$ & $\begin{array}{l}\text { Antisséptico, } \\
\text { adstringente, anti- } \\
\text { inflamatório }\end{array}$ & $9,09 \%$ \\
\hline Canafístula & $\begin{array}{l}\text { Senna } \\
\text { var. } \\
\text { (Schrad.) H. excelsa } \\
\text { Irwin \& Barneby }\end{array}$ & Caule & $\begin{array}{l}\text { Infusão, } \\
\text { decocto }\end{array}$ & $\begin{array}{l}\text { Hemorragia, } \\
\text { ferimento }\end{array}$ & $4,54 \%$ \\
\hline $\begin{array}{l}\text { Catinga } \mathrm{de} \\
\text { porco }\end{array}$ & $\begin{array}{l}\text { Terminalia } \\
\text { glabrescens Mart. }\end{array}$ & Caule & $\begin{array}{l}\text { Infusão, } \\
\text { decocto }\end{array}$ & $\begin{array}{l}\text { Dor de estomago, } \\
\text { cólica intestinal, } \\
\text { constipação }\end{array}$ & $9,09 \%$ \\
\hline Copaíba & $\begin{array}{l}\text { Copaifera } \\
\text { langsdorffii Desf. }\end{array}$ & Óleo & Ingerir c/água & $\begin{array}{l}\text { Cicatrizante, } \\
\text { infecções }\end{array}$ & $9,09 \%$ \\
\hline Fedegoso & $\begin{array}{l}\text { Senna } \\
\text { occidentalis (L.) } \\
\text { Lin }\end{array}$ & Folha & Decocto & $\begin{array}{l}\text { Abortivo, diarreia, } \\
\text { gripe, sarampo }\end{array}$ & $9,09 \%$ \\
\hline Jatobá & $\begin{array}{l}\text { Hymenaea } \\
\text { stigonocarpa var. } \\
\text { pubescens Benth. }\end{array}$ & Caule & $\begin{array}{l}\text { Maceração, } \\
\text { suco, xarope }\end{array}$ & $\begin{array}{l}\text { Anemia, gripe, } \\
\text { depurativo, dor no } \\
\text { corpo }\end{array}$ & $4,54 \%$ \\
\hline Mata pasto & $\begin{array}{l}\text { Senna obtusifolia } \\
\text { (L.) H. S. Irwin \& } \\
\text { Barneby }\end{array}$ & Raiz & Infusão & Psoríase & $4,54 \%$ \\
\hline
\end{tabular}


Tabela 1. Continuação.

\begin{tabular}{|c|c|c|c|c|c|}
\hline Família/NP & NC & PU & $\begin{array}{c}\text { Forma de } \\
\text { preparo }\end{array}$ & Indicação & $\begin{array}{c}\text { Frequência } \\
\text { de citação }\end{array}$ \\
\hline \multicolumn{6}{|l|}{ Fabaceae } \\
\hline Pata de vaca & $\begin{array}{l}\text { Bauhinia dubia } \mathrm{G} . \\
\text { Don }\end{array}$ & Caule & Decocto & $\begin{array}{l}\text { Antioxidante, } \\
\text { diabetes }\end{array}$ & $4,54 \%$ \\
\hline Pau d'óleo & $\begin{array}{l}\text { Copaifera } \\
\text { langsdorffii Desf. }\end{array}$ & Óleo & $\begin{array}{l}\text { Uso do óleo } \\
\text { em } \\
\text { ferimentos }\end{array}$ & $\begin{array}{l}\text { Tosse, asma, dor } \\
\text { no } \\
\text { enxaqueca }\end{array}$ & $9,09 \%$ \\
\hline Pau ferro & $\begin{array}{l}\text { Caesalpinia } \\
\text { ferrea var. } \\
\text { leiostachya } \\
\text { Benth }\end{array}$ & $\begin{array}{l}\text { Fruto, } \\
\text { caule }\end{array}$ & Decocto & $\begin{array}{l}\text { Gripe, azia, febre, } \\
\text { machucados, anti- } \\
\text { inflamatória }\end{array}$ & $9,09 \%$ \\
\hline Podói & $\begin{array}{l}\text { Copaifera } \\
\text { luetzelburgii } \\
\text { Harms } \\
\end{array}$ & Caule & Maceração & $\begin{array}{l}\text { Circulação, pedra } \\
\text { nos rins, próstata }\end{array}$ & $9,09 \%$ \\
\hline Sucupira & $\begin{array}{l}\text { Bowdichia } \\
\text { virgilioides Kunth }\end{array}$ & Semente & Decocto & $\begin{array}{l}\text { Inflamação da } \\
\text { garganta, coluna, } \\
\text { câncer }\end{array}$ & $9,09 \%$ \\
\hline Umburana & $\begin{array}{l}\text { Amburana } \\
\text { cearenses A.C. } \\
\text { Smith }\end{array}$ & $\begin{array}{l}\text { Semente, } \\
\text { caule }\end{array}$ & $\begin{array}{l}\text { Banho, } \\
\text { decocto, } \\
\text { inalação, } \\
\text { maceração }\end{array}$ & $\begin{array}{l}\text { Diarreia, } \\
\text { enxaqueca, } \\
\text { depurativo, } \\
\text { diurético } \\
\end{array}$ & $13,64 \%$ \\
\hline \multicolumn{6}{|l|}{ Gramíneas } \\
\hline Capim limão & $\begin{array}{l}\text { Cymbopogon } \\
\text { citratus (D.C.) } \\
\text { Stapf }\end{array}$ & Folha & $\begin{array}{l}\text { Chá infusão, } \\
\text { decocto }\end{array}$ & $\begin{array}{l}\text { Analgésico, } \\
\text { antirreumático, } \\
\text { estômago }\end{array}$ & $9,09 \%$ \\
\hline \multicolumn{6}{|l|}{ Lamiaceae } \\
\hline Alecrim & $\begin{array}{l}\text { Rosmarinus } \\
\text { officinalis L. }\end{array}$ & Folha & $\begin{array}{l}\text { Chá infusão, } \\
\text { maceração }\end{array}$ & $\begin{array}{l}\text { Energético, } \\
\text { reconstituinte }\end{array}$ & $13,64 \%$ \\
\hline Alfavaca & $\begin{array}{l}\text { Ocimum } \\
\text { gratissimum L. }\end{array}$ & $\begin{array}{l}\text { Folha, } \\
\text { flor, } \\
\text { caule }\end{array}$ & $\begin{array}{l}\text { Chá fervido, } \\
\text { infusão }\end{array}$ & $\begin{array}{l}\text { Tontura, dor no } \\
\text { corpo, gripe }\end{array}$ & $9,09 \%$ \\
\hline $\begin{array}{l}\text { Boldo } \\
\text { rasteiro }\end{array}$ & $\begin{array}{l}\text { Plectranthus } \\
\text { ornatus Codd. }\end{array}$ & Folha & $\begin{array}{l}\text { Chá fervido, } \\
\text { infusão, } \\
\text { maceração }\end{array}$ & $\begin{array}{l}\text { Má digestão, dor } \\
\text { de estomago, dor } \\
\text { de cabeça }\end{array}$ & $9,09 \%$ \\
\hline Hortelã & Mentha crispa L. & Folha & $\begin{array}{l}\text { Chá fervido, } \\
\text { maceração, } \\
\text { xarope }\end{array}$ & $\begin{array}{l}\text { Cólicas intestinais, } \\
\text { dor no corpo, } \\
\text { calmante }\end{array}$ & $36,36 \%$ \\
\hline Malvão & $\begin{array}{l}\text { Coleus } \\
\text { amboinicus Lour }\end{array}$ & Folha & $\begin{array}{l}\text { Decocto, } \\
\text { infusão, } \\
\text { xarope }\end{array}$ & $\begin{array}{l}\text { Febre, diarreia, } \\
\text { dor de garganta e } \\
\text { ouvido, tosse }\end{array}$ & $4,54 \%$ \\
\hline Manjericão & $\begin{array}{l}\text { Ocimum } \\
\text { gratissimum L. }\end{array}$ & Folha & Infusão & $\begin{array}{l}\text { Gripe, dor de } \\
\text { cabeça, intestino }\end{array}$ & $9,09 \%$ \\
\hline \multicolumn{6}{|c|}{ Lecythidaceae } \\
\hline Sapucaia & $\begin{array}{l}\text { Lecythis pisonis } \\
\text { Cambess }\end{array}$ & Caule & Decocto & Diabetes & $4,54 \%$ \\
\hline \multicolumn{6}{|l|}{ Liliaceae } \\
\hline Alho & Allium sativum L. & Fruto & $\begin{array}{l}\text { Decocto, } \\
\text { infusão }\end{array}$ & Gripe, hipertensão & $9,09 \%$ \\
\hline Babosa & Aloe vera L. & Folha & $\begin{array}{l}\text { Cataplasma, } \\
\text { suco }\end{array}$ & $\begin{array}{l}\text { Inflamação na } \\
\text { garganta }\end{array}$ & $9,09 \%$ \\
\hline Milindro & Asparagus sp. & Folha & Chá infusão & $\begin{array}{l}\text { Nervosismo, } \\
\text { problemas } \\
\text { circulatórios }\end{array}$ & $4,54 \%$ \\
\hline
\end{tabular}


Tabela 1. Continuação.

\begin{tabular}{|c|c|c|c|c|c|}
\hline Família/NP & NC & PU & $\begin{array}{c}\text { Forma de } \\
\text { preparo }\end{array}$ & Indicação & $\begin{array}{c}\text { Frequência } \\
\text { de citação }\end{array}$ \\
\hline \multicolumn{6}{|l|}{ Malpighiceae } \\
\hline Acerola & $\begin{array}{l}\text { Malpighia } \\
\text { emarginata DC. }\end{array}$ & Folha & Suco & Diabetes, gripe & $4,54 \%$ \\
\hline \multicolumn{6}{|l|}{ Malvaceae } \\
\hline Algodão & $\begin{array}{l}\text { Gossypium } \\
\text { herbaceum L. }\end{array}$ & Folha & $\begin{array}{l}\text { Chá infusão, } \\
\text { xarope, } \\
\text { maceração }\end{array}$ & $\begin{array}{l}\text { Gripe, fígado, } \\
\text { machucados }\end{array}$ & $9,09 \%$ \\
\hline Chichá & 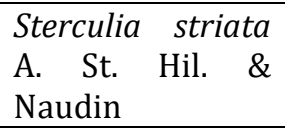 & Folha & $\begin{array}{l}\text { Decocto, } \\
\text { infusão }\end{array}$ & $\begin{array}{l}\text { Picada de cobra, } \\
\text { dor nas pernas }\end{array}$ & $9,09 \%$ \\
\hline Mutamba & $\begin{array}{l}\text { Guazuma } \\
\text { ulmifolia Lam. }\end{array}$ & Caule & Decocto & $\begin{array}{l}\text { Antioxidantes, } \\
\text { anticancerígenas }\end{array}$ & $4,54 \%$ \\
\hline \multicolumn{6}{|l|}{ Moraceae } \\
\hline Amora & Morus nigra L. & $\begin{array}{l}\text { Caule, } \\
\text { Folha }\end{array}$ & Infusão & $\begin{array}{l}\text { Hipertensão, } \\
\text { diarreia }\end{array}$ & $4,54 \%$ \\
\hline Mama cadela & $\begin{array}{l}\text { Brosimum } \\
\text { gaudichaudii } \\
\text { Tréc. } \\
\end{array}$ & Folha & Maceração & $\begin{array}{l}\text { Coluna, sangue, } \\
\text { infecções, } \\
\text { depurativo }\end{array}$ & $4,54 \%$ \\
\hline \multicolumn{6}{|l|}{ Myrtaceae } \\
\hline Araçá goiaba & $\begin{array}{l}\text { Psidium } \\
\text { longipetiolatum } \\
\text { D. Legrand } \\
\end{array}$ & Folha & Maceração & $\begin{array}{l}\text { Calmante, } \\
\text { diurético }\end{array}$ & $4,54 \%$ \\
\hline Eucalipto & $\begin{array}{l}\text { Eucalyptus } \\
\text { globulus Labill }\end{array}$ & Folha & $\begin{array}{l}\text { Banho, } \\
\text { inalação, } \\
\text { infusão } \\
\end{array}$ & Gripe, febre & $4,54 \%$ \\
\hline Goiaba & $\begin{array}{l}\text { Psidium guajava } \\
\text { L. }\end{array}$ & Folha & $\begin{array}{l}\text { Decocto, } \\
\text { infusão, } \\
\text { maceração, pó }\end{array}$ & $\begin{array}{l}\text { Adstringente, } \\
\text { antioxidante, } \\
\text { digestivo } \\
\end{array}$ & $4,54 \%$ \\
\hline Pitanga & $\begin{array}{l}\text { Eugenia uniflora } \\
\text { L. }\end{array}$ & $\begin{array}{l}\text { Folha, } \\
\text { fruto }\end{array}$ & $\begin{array}{l}\text { Decocto, } \\
\text { infusão }\end{array}$ & $\begin{array}{l}\text { Anti-inflamatório, } \\
\text { diurético, diminui } \\
\text { a pressão }\end{array}$ & $9,09 \%$ \\
\hline \multicolumn{6}{|l|}{ Musaceae } \\
\hline Banana & $\begin{array}{l}\text { Musa paradisiaca } \\
\text { L. }\end{array}$ & $\begin{array}{l}\text { Flor, } \\
\text { selva }\end{array}$ & $\begin{array}{l}\text { Mucilagem } \\
\text { diluída }\end{array}$ & $\begin{array}{l}\text { Gripe, diarreia, } \\
\text { queimadura }\end{array}$ & $4,54 \%$ \\
\hline \multicolumn{6}{|c|}{ Nyctaginaceae } \\
\hline Pega pinto & $\begin{array}{l}\text { Boerhavia difusa } \\
\text { L. }\end{array}$ & $\begin{array}{l}\text { Folha, } \\
\text { raiz }\end{array}$ & Infusão & $\begin{array}{l}\text { Diurético, } \\
\text { inflamação do } \\
\text { útero }\end{array}$ & $9,09 \%$ \\
\hline \multicolumn{6}{|l|}{ Oxalidaceae } \\
\hline Carambola & $\begin{array}{l}\text { Averrhoa } \\
\text { carambola L. }\end{array}$ & Fruto & Suco & $\begin{array}{l}\text { Antitérmico, } \\
\text { hipertensão } \\
\text { arterial e diabetes }\end{array}$ & $4,54 \%$ \\
\hline \multicolumn{6}{|c|}{ Passifloraceae } \\
\hline Maracujá & $\begin{array}{l}\text { Passiflora edulis } \\
\text { Sims }\end{array}$ & $\begin{array}{l}\text { Folha, } \\
\text { fruto }\end{array}$ & $\begin{array}{l}\text { Decocto, } \\
\text { infusão }\end{array}$ & $\begin{array}{l}\text { Hipotensão, } \\
\text { calmante, insônia }\end{array}$ & $9,09 \%$ \\
\hline \multicolumn{6}{|l|}{ Pedaliaceae } \\
\hline Gergelim & $\begin{array}{l}\text { Sesamum } \\
\text { indicum L. }\end{array}$ & Semente & $\begin{array}{l}\text { Decocto, } \\
\text { infusão }\end{array}$ & Pneumonia & $4,54 \%$ \\
\hline \multicolumn{6}{|c|}{ Phytolacaceae } \\
\hline Tipi & $\begin{array}{l}\text { Petiveria alliacea } \\
\text { L. }\end{array}$ & $\begin{array}{l}\text { Planta } \\
\text { inteira }\end{array}$ & Chá infusão & Gripe, mau olhado & $4,54 \%$ \\
\hline
\end{tabular}


Tabela 2. Continuação.

\begin{tabular}{|c|c|c|c|c|c|}
\hline Família/NP & NC & PU & $\begin{array}{c}\text { Forma de } \\
\text { preparo }\end{array}$ & Indicação & $\begin{array}{c}\text { Frequência } \\
\text { de citação }\end{array}$ \\
\hline \multicolumn{6}{|l|}{ Punicaceae } \\
\hline Romã & $\begin{array}{l}\text { Punica granatum } \\
\text { L. }\end{array}$ & $\begin{array}{l}\text { Casca do } \\
\text { fruto }\end{array}$ & $\begin{array}{l}\text { Chá infusão, } \\
\text { maceração, } \\
\text { suco }\end{array}$ & Dor de garganta & $9,09 \%$ \\
\hline \multicolumn{6}{|l|}{ Rubiaceae } \\
\hline Jenipapo & $\begin{array}{l}\text { Genipa } \\
\text { americana } \mathrm{L} .\end{array}$ & $\begin{array}{l}\text { Caule, } \\
\text { fruto }\end{array}$ & $\begin{array}{l}\text { Decocto, } \\
\text { infusão }\end{array}$ & $\begin{array}{l}\text { Dor no joelho, } \\
\text { depurativo }\end{array}$ & $9,09 \%$ \\
\hline Noni & $\begin{array}{l}\text { Morinda citrifolia } \\
\text { L. }\end{array}$ & $\begin{array}{l}\text { Folha, } \\
\text { fruto }\end{array}$ & Suco & $\begin{array}{l}\text { Dores de cabeça, } \\
\text { anti-inflamatório, } \\
\text { gastrite }\end{array}$ & $9,09 \%$ \\
\hline \multicolumn{6}{|l|}{ Rutaceae } \\
\hline Arruda & $\begin{array}{l}\text { Ruta graveolens } \\
\text { L. }\end{array}$ & Folha & $\begin{array}{l}\text { Maceração, } \\
\text { inalação, chá } \\
\text { infusão }\end{array}$ & $\begin{array}{l}\text { Cólicas, digestão, } \\
\text { hemorroidas }\end{array}$ & $13,64 \%$ \\
\hline Laranja & $\begin{array}{l}\text { Citrus sinensis } \\
\text { (L.) Osbeck. }\end{array}$ & $\begin{array}{l}\text { Cascas } \\
\text { do fruto, } \\
\text { folha }\end{array}$ & $\begin{array}{l}\text { Decocto, } \\
\text { infusão, } \\
\text { maceração, } \\
\text { suco }\end{array}$ & $\begin{array}{l}\text { Calmante, febre, } \\
\text { diarreia, } \\
\text { hipertensão, } \\
\text { cólica intestinal, } \\
\text { dor de cabeça }\end{array}$ & $9,09 \%$ \\
\hline Lima & $\begin{array}{l}\text { Citrus } \\
\text { aurantifolia } \\
\text { (Christm.) } \\
\text { Swingle } \\
\end{array}$ & $\begin{array}{l}\text { Folha, } \\
\text { caule }\end{array}$ & $\begin{array}{l}\text { Decocto, } \\
\text { infusão }\end{array}$ & $\begin{array}{l}\text { Taquicardia, } \\
\text { calmante }\end{array}$ & $9,09 \%$ \\
\hline Limão & $\begin{array}{l}\text { Citrus limon (L.) } \\
\text { Burm. }\end{array}$ & $\begin{array}{l}\text { Caule, } \\
\text { folha, } \\
\text { fruto }\end{array}$ & $\begin{array}{l}\text { Inalação, } \\
\text { decocto, } \\
\text { infusão }\end{array}$ & $\begin{array}{lr}\text { Febre, } & \text { gripe, } \\
\text { fortalece } & \text { os } \\
\text { dentes } & \\
\end{array}$ & $13,64 \%$ \\
\hline Manacá & $\begin{array}{l}\text { Spiranthela } \\
\text { odorantíssima A. } \\
\text { St.-Hil. }\end{array}$ & Raiz & Infusão & $\begin{array}{l}\text { Inflamações } \\
\text { uterinas, dor de } \\
\text { cabeça, estômago }\end{array}$ & $4,54 \%$ \\
\hline \multicolumn{6}{|l|}{ Salicaceae } \\
\hline Salgueiro & $\begin{array}{l}\text { Salix babylonica } \\
\text { L. }\end{array}$ & $\begin{array}{l}\text { Caule, } \\
\text { flor }\end{array}$ & Decocto & Alivia dores, febre & $4,54 \%$ \\
\hline \multicolumn{6}{|l|}{ Solanaceae } \\
\hline Jurubeba & $\begin{array}{l}\text { Solanum } \\
\text { paniculatum L. }\end{array}$ & $\begin{array}{l}\text { Fruto, } \\
\text { raiz }\end{array}$ & Decocto & $\begin{array}{ll}\text { Pele ressecada, } \\
\text { fígado }\end{array}$ & $4,54 \%$ \\
\hline $\begin{array}{l}\text { Melancia da } \\
\text { praia }\end{array}$ & $\begin{array}{l}\text { Solanum } \\
\text { agrarium Sendtn. }\end{array}$ & $\begin{array}{l}\text { Raiz, } \\
\text { fruto }\end{array}$ & Decocto & $\begin{array}{l}\text { Manchas de pele } \\
\text { (panos), urticária, } \\
\text { tuberculose }\end{array}$ & $27,27 \%$ \\
\hline \multicolumn{6}{|l|}{ Urticaceae } \\
\hline Urtiga & Urtica dioica L. & Folha & Decocto & $\begin{array}{l}\text { Anemia, } \\
\text { anti-inflamatório }\end{array}$ & $9,09 \%$ \\
\hline \multicolumn{6}{|l|}{ Verbenaceae } \\
\hline Erva cidreira & $\begin{array}{l}\text { Melissa officinalis } \\
\text { L. }\end{array}$ & Folha & $\begin{array}{l}\text { Decocto, } \\
\text { infusão }\end{array}$ & $\begin{array}{l}\text { Calmante, } \\
\text { expectorante, } \\
\text { cólicas }\end{array}$ & $18,18 \%$ \\
\hline \multicolumn{6}{|l|}{ Violaceae } \\
\hline Papaconha & $\begin{array}{l}\text { Hybanthus } \\
\text { lanatus (A.St.- } \\
\text { Hil.) Baill. }\end{array}$ & Raiz & Infusão & $\begin{array}{ll}\text { Gripe, } & \text { febre, } \\
\text { sarampo } & \end{array}$ & $4,54 \%$ \\
\hline
\end{tabular}


Tabela 3. Continuação.

\begin{tabular}{|c|c|c|c|c|c|}
\hline Família/NP & NC & PU & $\begin{array}{c}\text { Forma de } \\
\text { preparo }\end{array}$ & Indicação & $\begin{array}{c}\text { Frequência } \\
\text { de citação }\end{array}$ \\
\hline \multicolumn{6}{|c|}{ Zingiberaceae } \\
\hline Açafrão & Curcuma longa L. & Raiz & $\begin{array}{l}\text { Infusão, } \\
\text { decocto }\end{array}$ & $\begin{array}{l}\text { Sarampo, } \\
\text { catapora, gripe }\end{array}$ & $9,09 \%$ \\
\hline Gengibre & $\begin{array}{l}\text { Zingiber } \\
\text { officinale Roscoe }\end{array}$ & Raiz & $\begin{array}{l}\text { Decocto, } \\
\text { infusão, } \\
\text { maceração }\end{array}$ & $\begin{array}{l}\text { Estômago, } \\
\text { expectorante }\end{array}$ & $13,64 \%$ \\
\hline
\end{tabular}

Fonte: Arrais et al. (2017), Dantas e Torres (2019), Gonçalves et al. (2018), Menezes et al. (2019). NP - Nome popular, NC - Nome científico e PU - Parte utilizada. ${ }^{* *}$ Cataplasma - papa medicamentosa feita de farinhas, polpas ou pó de raízes e folhas que se aplica sobre alguma parte do corpo dolorida ou inflamada. Decocto - ação de ferver, cozimento. Inalação - ato ou efeito de inalar, absorção de medicamentos. Infusão - processo de mergulhar em água fervente qualquer substância para dela extrair princípios medicamentosos ou alimentícios; líquido que se obtém por este processo. Maceração - consiste em retirar de um material substâncias que possuem princípios ativos. Mucilagem - substância vegetal diluída. Xarope- solução concentrada.

Após a identificação das espécies realizadas juntamente com os moradores e a realização de levantamentos bibliográficos constatou que muitas dessas espécies que foram citadas são típicas do Cerrado, no entanto, existem algumas delas que ocorrem em outros biomas como da Caatinga e Mata Atlântica.

Em se tratando das espécies mais citadas pelos entrevistados, verificou-se que as espécies mais usadas são erva doce Pimpinella anisum L. e hortelã Mentha crispa L. com cerca de 36,36\%, melancia da praia Solanum agrarium Sendtn. com 27,27\%, erva cidreira Lippia alba (Mill.) N.E.Br. com 18,18\%, seguido do alecrim Rosmarinus officinalis L., gengibre Zingiber officinale Roscoe, imburana Amburana cearensis e limão Citrus limon (L.) Burm. com $13,64 \%$ e do pequi Caryocar coriaceum Wittm com $4,54 \%$.

É importante ressaltar que, todas estas espécies elencadas na Tabela 1 acima, possuem uma finalidade específica para o tratamento de enfermidades as quais acometem a saúde das pessoas como, diarreia, febre, hipertensão, infecção no sistema urinário, no sistema respiratório, regulador menstrual, contusão, úlcera, colesterol, entre outras.

Quanto à parte vegetal utilizada nas preparações dos remédios caseiros, observouse uma frequência maior de uso das folhas (nove citações), seguido de caule e fruta (seis citações), raízes (quatro citações), flores (duas citações) e óleo (uma citação). Percebeu-se desse modo que houve uma predominância considerável no que se refere ao uso de folhas.

De acordo David et al. (2016), relacionado ao saber popular das plantas medicinais, houve uma semelhança nos resultados do seu estudo, onde constatou-se também que a parte da planta mais utilizada pelas pessoas é a folha, seguida do caule, fruto, flor e da raiz. Isso se dá pelo fato de que a folha no preparo dos remédios caseiros é um costume que demonstra cuidado com os recursos da região, corroborando na conservação das plantas e ainda, por serem encontradas durante quase todo o ano.

Dentre as doenças mais citadas pelos moradores que são tratadas pelas plantas medicinais se destacaram àquelas que se referem ao aparelho respiratório, onde destacaram (febre, gripe e tosse), seguidos pelas dores (barriga, cabeça, coluna, dente, fígado, estômago, rins), antioxidantes, infecções e cicatrizantes, houve ainda outras citações relevantes, a exemplo de anti-inflamatórios, calmantes, diabetes, inflamações, e pressão alta.

Em uma pesquisa realizada por Dantas e Torres (2019), foi possível obter resultados semelhantes a este, onde as plantas medicinais possuem a capacidade de curar 
e/ou aliviar problemas que acometem as pessoas, onde os mais frequentes são problemas no sistema respiratório, digestório e cardíaco, os entrevistados destacaram como exemplo, gripes, febres, dores no corpo e diarreia.

Este resultado assemelha-se ainda com o estudo de David et al. (2016), que trata do conhecimento popular das plantas medicinais, onde constatou-se que a maioria dos entrevistados afirmaram que existem plantas que curam e que fazem o uso destas sempre que necessário, sendo elas utilizadas em casos de tosse, gripe, resfriado, problemas digestivos, como calmante e mal-estar.

Foram identificadas muitas espécies próximas às residências na comunidade (Figura 2), as quais são destinadas ao uso no tratamento de problemas de saúde como, por exemplo açafrão Curcuma longa L., arruda Ruta graveolens L., banana Musa paradisiaca L., capim limão Cymbopogon citratus (D.C.) Stapf., Hortelã Mentha crispa L., manjericão Ocimum gratissimum L., melancia de praia Solanum agrarium Sendtn., limão Citrus limon (L.) Burm., entre outras.
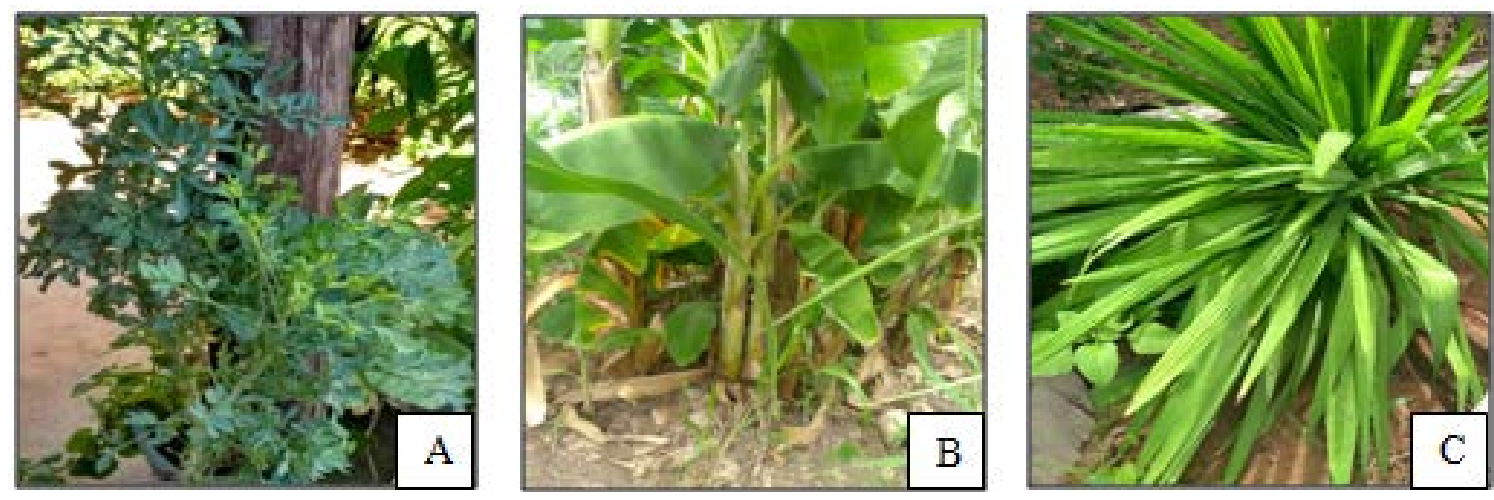

Figura 2. Espécies identificadas nos quintais dos moradores da comunidade, arruda (A), banana (B) e capim limão (C).

Foi possível verificar que cerca de $60 \%$ das espécies citadas são cultivadas nos próprios quintais das famílias, no qual para isso de acordo os moradores entrevistados, são realizados o preparo do terreno (limpeza da área e adubação), plantio, cuidado e posteriormente, o uso destas espécies.

De acordo Rodrigues et al. (2018), o cultivo de ervas medicinais é algo bastante comum nos espaços que contornam a casa, isso pelo fato de serem de maior facilidade no seu acesso, além dos cuidados que se exigem, levando ainda em consideração a relevância de determinadas espécies para as pessoas, motivo este que influencia ainda mais na opção de escolha pela proximidade do cultivo das plantas.

Segundo Dias e Laureano (2009), essa é uma prática muito utilizada pelas pessoas para o tratamento de muitos tipos de enfermidades, baseada no conhecimento tradicional que cada comunidade possui, sendo utilizado de muitas maneiras como, por exemplo, remédios caseiros utilizados na forma de chás, banhos, entre outros.

De acordo Freitas (2016) "os espaços domésticos, comumente denominados de quintais, são sistemas complexos nos quais grande diversidade de espécies é manejada ou conservada." São muitas as plantas que possuem o potencial medicinal no alívio e cura de muitas enfermidades, sendo muitas delas encontradas nos quintais das residências principalmente nas comunidades rurais (Figura 3). 


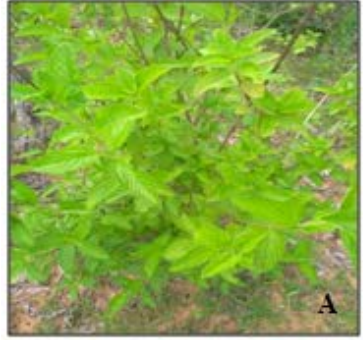

Alecrim (Rosmarimus officinalis L.)

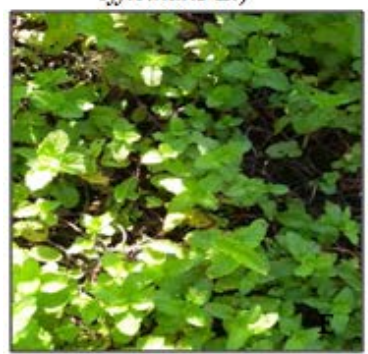

Hortelã (Mentha crispa L.)

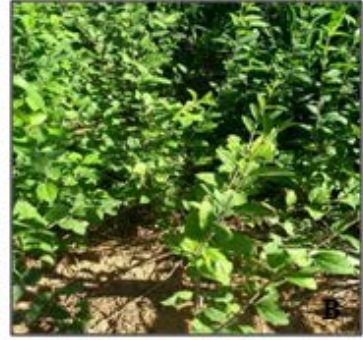

Erva cidreira (Lippia alba (Mill.) N.E.Br.)

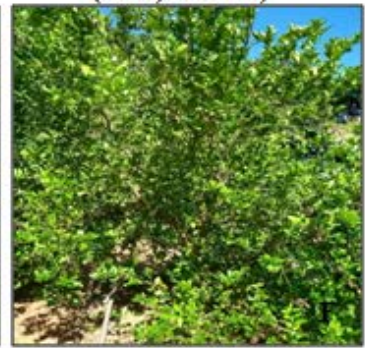

Limão (Citrus limon (L.) Burm.)

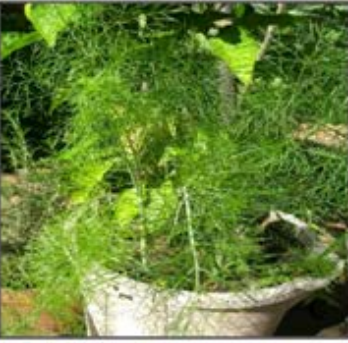

Erva doce (Pimpinella anisum L.)

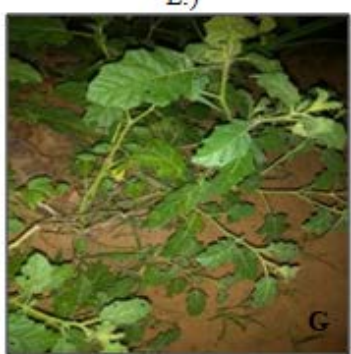

Melancia da praia (Solamum agrarium Sendtn.)

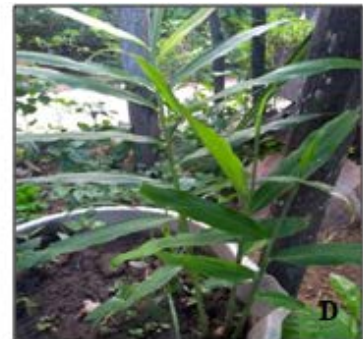

Gengibre (Zingiber officinale Roscoe)

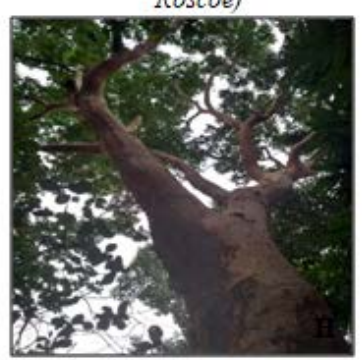

Umburana (Amburana cearensis)

Figura 3. Ilustração das espécies mais citadas pelos entrevistados.

Essas espécies possuem grande relevância para as pessoas em que estas foram adquirindo mais conhecimento sobre o uso das plantas medicinais, além de realizar levantamentos no que se refere a quantidade, indicações e uso nas comunidades, identificando ainda as culturas de cada região (Tabuti, 2007).

\section{Considerações finais}

Por meio das informações obtidas por meio dos moradores foi possível realizar o levantamento etnobotânico das plantas medicinais ocorrentes na comunidade rural de Santa Marta.

As espécies mais identificadas foram erva doce Pimpinella anisum L., hortelã Mentha crispa L., melancia da praia Solanum agrarium Sendtn., erva cidreira Lippia alba (Mill.) N.E.Br., seguido do alecrim Rosmarinus officinalis L., gengibre Zingiber officinale Roscoe, umburana Amburana cearensis A.C. Smith, limão Citrus limon (L.) Burm. e o pequi Caryocar coriaceum Wittm. Em relação ao conhecimento sobre as plantas medicinais notou-se que, muitos dos moradores da comunidade possuem o conhecimento no que se refere ao cultivo, preparação e a que se destina a espécie.

Percebeu-se que, as plantas mais usadas pela comunidade estudada estão de acordo com o uso em outras comunidades, como Serra do Passa-Tempo (PI) (Almeida Neto et al., 2015) e na Comunidade de Capanema (PA) (Leão et al., 2016). No entanto, é perceptível que o conhecimento na população estudada precisa ser trabalhado com mais frequência por meio da pesquisa científica, da aproximação de pesquisadores com as comunidades rurais, a fim de proporcionar as mesmas informações sobre a temática abordada.

Neste contexto, pode-se salientar que a pesquisa voltada para o campo das plantas medicinais é promissora, isso por estas possuírem grande potencial medicinal, contudo tem se comprovado cientificamente a pesquisa sobre o tema em relação ao uso popular destas. Dessa forma, os resultados da pesquisa nos mostram que as plantas medicinais não 
só são usadas como uma prática de medicina alternativa pela Comunidade de Santa Marta, como também é parte de uma cultura que a comunidade deve conservar.

Ao construir essa relação entre comunidade e o conhecimento sobre uso das plantas medicinais se torna de grande valia para a vida das pessoas, propiciando a contribuição para a conservação da cultura regional, contribuindo assim na sua valorização.

\section{Conflito de interesses}

Os autores declaram não haver conflito de interesses.

\section{Referências}

Albuquerque, U. P.; Lucena, R. F. P.; Cunha, L. V. F. C. Métodos e técnicas de pesquisa etnobotânica. 2. ed. Recife-PE: COMUNIGRAF, 2008.

Almeida Neto, J. R.; Barros, R. F. M. de; Silva, P. R. R. Uso de plantas medicinais em comunidades rurais da Serra do Passa-Tempo, Estado do Piauí, Nordeste do Brasil. Revista Brasileira de Biociências, v. 13, n. 3, p. 165-175, 2015.

Arrais, F. D. C. L.; Viana, R. H. O.; Silva, W. A.; Pereira, B. L.; Ferreira, G. Levantamento etnobotânico nas margens do Córrego Machado - Palmas, Tocantins, Brasil. FLOVET -

Boletim do Grupo de Pesquisa da Flora, Vegetação e Etnobotânica, v. 1, n. 9, p. 58-68, 2017.

Baptistel, A. C.; Coutinho, J. M. C. P.; Lins Neto, E. M. F.; Monteiro, J. M. Plantas medicinais utilizadas na Comunidade Santo Antônio, Currais, Sul do Piauí: um enfoque etnobotânico. Revista Brasileira de Plantas Medicinais, v. 16, n. 2 suppl 1, p. 406-425, 2014. https://doi.org/10.1590/1983-084X/12_137

Bastos, E. M.; Chaves e Silva, M. E.; Vieira, F. J.; Barros, R. F. M. Conhecimento botânico local em uma área de assentamento rural no Piaú, Nordeste do Brasil. Gaia Scientia, v. 12, n. 2 , p.12-33, 2018. https://doi.org/10.22478/ufpb.1981-1268.2018v12n2.34918

Dantas, J. I. M.; Torres, A. M. Abordagem etnobotânica de plantas medicinais em uma comunidade rural do sertão alagoano. Diversitas Journal, v. 4, n. 1, p. 39, 2019. https://doi.org/10.17648/diversitas-journal-v4i1.663

David, M.; Oliveira, G. M. S.; Pinheiro, M. P. V. O saber popular e as plantas presentes nos quintais de uma comunidade escolar em Rondonópolis, Mato Grosso. Biodiversidade, v. 15, n. 2, p. 75-84, 2016.

Dias, J. E.; Laureano, L. C. Farmacopéia do cerrado. Goiânia: Articulação Pacari, 2009.

Franco, E. A. P.; Barros, R. F. M. Uso e diversidade de plantas medicinais no Quilombo Olho d'Água dos Pires, Esperantina, Piauí. Revista Brasileira de Plantas Medicinais, v. 8, n. 3, p. 78-88, 2006.

Freitas, A. V. L. 0 espaço doméstico dos quintais e a conservação de plantas medicinais na Comunidade São João da Várzea, Mossoró-RN. Mossoró: Universidade Federal Rural do Semi Árido, 2016. (Tese de doutorado).

IBGE - Instituto Brasileiro de Geografia e Estatística. Mapas de biomas e de vegetação. 2015. Disponível em: <https://mapas.ibge.gov.br/tematicos/vegetacao.html>. Acesso em: 31 mar. 2019.

Gonçalves, M. D. M. M.; Cajaiba, R. L.; Santos, W. B.; Sousa, E. S.; Martins, J. S. C.; Pereira, K. S.; Sousa, V. A. Estudo etnobotânico do conhecimento e uso de plantas medicinais em Santa

Rev. Bras. Gest. Amb. Sustent., 2020, vol. 7, n. 17, p. 1483-1498. 
Luzia, Maranhão, Brasil. Revista Ibero-Americana de Ciências Ambientais, v. 9, n. 5, p. 12-21, 2018. https://doi.org/10.6008/CBPC2179-6858.2018.005.0002

Leão, V. M.; Lucas, F. C. A.; Reis, A. S.; Martins, A. C. C. T.; Costa, J. C. M.. Usos e benefícios das plantas em comunidades rurais de Capanema, Pará, Brasil. Cadernos de Agroecologia, v. 10, n. 3, p. 1689-1699, 2016.

Lima, J. R. S. Etnobotânica no Cerrado: um estudo no Assentamento Santa Rita, Jataí (GO). Goiânia: Universidade Federal de Goiás, 2013. (Dissertação mestrado).

Lopes Sobrinho, O. P.; Pereira, A. I. S.; Cantanhede, E. K. P.; Xavier, R. S.; Oliveira, L. S.; Pereira, A. G. S.; Cruz, C. H. G. Estudo etnobotânico de plantas medicinais e indicações terapêuticas no Povoado Fomento, Município de Codó, Maranhão, Brasil. Revista Cubana de Plantas Medicinales, v. 23, n. 1, p. 1-23, 2018.

Menezes, S. A.; Portela, B. Y. M.; Lima, L. B.; Vandesmet, L. C. S. Levantamento etnobotânico de espécies medicinais do Nordeste Brasileiro com potencial anti-inflamatório. Brazilian Journal of Development, v. 5, n. 10, p. 18238-18249, 2019. https://doi.org/10.34117/ bjdv5n10-083

Messias, M. C. T. B.; Carmo, F. F. Flora e vegetação em substratos ferruginosos do Sudeste do Quadrilátero Ferrífero. In: Carmo, F. F.; Kamino, L. H. Y. (Orgs.). Geossistemas ferruginosos no Brasil. Belo Horizonte:, Instituto Prístino, 2015. p. 335-360.

Minayo, M. C. S.; Deslandes, S. F.; Gomes, R. Pesquisa social: teoria, método e criatividade. 28. ed. Petrópolis: Vozes, 2009.

Pauli, P. T.; Rios, R. S.; Bieski, I. G. C.; Silva, J. S. Estudo etnobotânico de plantas medicinais em bairros de Juína, Mato Grosso, Brasil. Revista Saúde Viva Multidisciplinar da AJES, v. 1, n. 1, p. 117-156, 2018.

Rodrigues, A. N. C.; Martins, J. G. S.; Teixeira, K. S.; Maués, T. M. S.; Santos, E. M.; Rosal, L. F. Conhecimento popular sobre o uso plantas medicinais no assentamento Agrocasa, em São Francisco do Pará, Pará, Brasil. Anais do VI Congresso Latino-americano de Agroecologia, X Congresso Brasileiro de Agroecologia, V Seminário de Agroecologia do Distrito Federal e Entorno, v. 13, p. 6, 2018.

Rodrigues, A. P.; Andrade, L. H. C. Levantamento etnobotânico das plantas medicinais utilizadas pela comunidade de Inhamã, Pernambuco, Nordeste do Brasil. Revista Brasileira de Plantas Medicinais, v. 16, n. 3 suppl.1, p.721-730, 2014. https://doi.org/10.1590/1983-084x/08_159

Souza, J. S. S.; Gomes, E. C.; Rocha, T. C.; Böger, B. Uso de plantas medicinais por comunidades do Município de Curitiba. Divers@! Revista Eletronica Interdisciplinar, v. 10, n. 2, p. 91-97, 2017. https://doi.org/10.5380/diver.v10i2.54098

Souza, L. J. A investigação do conhecimento e uso de plantas medicinais na Região do Distrito Prata, Município de Monte Alegre de Goiás-Go. Brasília: Universidade de Brasília, 2015.

Tabuti, J. R. S. The uses, local perceptions and ecological status of 16 woody species of Gadumire Sub-County, Uganda. Biodiversity and Conservation, v. 16, n. 6, p. 1901-1915, 2007. https://doi.org/10.1007/s10531-006-9097-7

Informação da Licença: Este é um artigo Open Access distribuído sob os termos da Licença Creative Commons Attribution, que permite uso irrestrito, distribuição e reprodução em qualquer meio, desde que a obra original seja devidamente citada. 